\title{
Activity-Dependent Enhancement of Synaptic Transmission in Hippocampal Slices Treated with the Phosphatase Inhibitor Calyculin A
}

\author{
Caroline E. Herron and Robert C. Malenka \\ Departments of Psychiatry and Physiology, University of California, San Francisco, California 94143
}

The role of protein phosphatases in regulating synaptic transmission in the CA1 region of the hippocampus was examined using slices pretreated with calyculin A, a specific inhibitor of protein phosphatases 1 and $2 A$. Stimulation of afferents at $1 \mathrm{~Hz}$ (but not $0.1 \mathrm{~Hz}$ ) for periods of 5-10 min caused a long-lasting enhancement of synaptic transmission. The increase in synaptic responses was not due to a change in fiber excitability, as there was a shift to the left in the input-output curve following the synaptic enhancement- The enhancement was observed only in the input that received the $1 \mathrm{~Hz}$ stimulation and not in an independent control pathway, indicating that the increase in synaptic strength is input specific and limited to repetitively activated synapses. Applying $1 \mathrm{~Hz}$ stimulation when synaptic transmission was blocked by replacing extracellular $\mathrm{Ca}^{2+}$ with $\mathbf{M g}^{2+}$ prevented or significantly reduced any change in synaptic efficacy after reperfusion with normal $\mathrm{Ca}^{2+}$-containing medium. In contrast, $1 \mathrm{~Hz}$ stimulation given when synaptic transmission was blocked by non-NMDA and NMDA glutamate receptor antagonists still caused a synaptic enhancement following washout of the antagonists. The enhancement of synaptic transmission also was not blocked by loading CA1 cells with the calcium chelator BAPTA. Thus, influx of $\mathrm{Ca}^{2+}$ into presynaptic elements is required for the synaptic enhancement elicited by $1 \mathrm{~Hz}$ stimulation in calyculin A-treated hippocampal slices. Consistent with the activation of processes that cause an increase in transmitter release, the magnitude of paired-pulse facilitation decreased following the synaptic enhancement, and the NMDA receptor-mediated component of the synaptic response was increased by $1 \mathrm{~Hz}$ stimulation. These results suggest that when protein phosphatases are inhibited by calyculin A, prolonged periods of $1 \mathrm{~Hz}$ stimulation lead to activation of presynaptic $\mathrm{Ca}^{2+}$-dependent protein kinases, resulting in a persistent increase in evoked transmitter release. They also indicate that the activity of presynaptic protein phosphatases is critically important for limiting increases in synaptic strength following repetitive afferent activity.

Received Oct. 1, 1993; revised Mar. 25, 1994; accepted Apr. 6, 1994

This work was supported by grants from the Klingenstein Foundation, the National Institute of Mental Health, the McKnight Foundation, and the National Alliance for Research on Schizophrenia and Depression. We thank R. Mulkey, S. Kombian, D. Spillane, S. Nicola, and J. Cummings for critical reading of the manuscript.

Correspondence should be addressed to Robert C. Malenka, Department of Psychiatry, LPPI, Box F-0984, University of California, San Francisco, CA 94143. Copyright $(1994$ Society for Neuroscience $0270-6474 / 94 / 146013-08 \$ 05.00 / 0$
[Key words: presynaptic, hippocampus, synaptic enhancement, phosphatase inhibitor, calcium-dependent kinase, calcium]

Many aspects of neuronal function are influenced by protein phosphorylation, including neuronal excitability, transmitter biosynthesis, and transmitter release. Much work has focused specifically on the role of protein kinases in the pre- or postsynaptic regulation of synaptic transmission. Specific kinases, the activity of which have been shown to infiuence synaptic transmission, include protein kinase $\mathrm{C}(\mathrm{PKC}), \mathrm{Ca}^{2+} /$ calmodulin-dependent protein kinase type II (CaMKII), cGMP-dependent protein kinase (PKG), and cAMP-dependent protein kinase (PKA) (for reviews, see Schulman, 1991; Walaas and Greengard, 1991). Several of these kinases are also thought to be involved in certain forms of synaptic plasticity, most notably long-term potentiation (LTP) (Madison et al., 1991; Bliss and Collingridge, 1993)

Regulation of the phosphorylation state of phosphoproteins can be achieved not only by modifying the activity of specific protein kinases but also by modulation of protein phosphatase activity. Although there have been many studies on neuronal protein kinases and their effects on synaptic transmission, much less is known regarding the role of specific protein phosphatases. Protein phosphatases can be divided into two broad classes, serine/threonine protein phosphatases and tyrosine protein phosphatases. Most biochemical and molecular studies have concentrated on the members of the serine/threonine protein phosphatase family that include protein phosphatase I (PP-1), protein phosphatase $2 \mathrm{~A}$ (PP-2A), a $\mathrm{Ca}^{2+} / \mathrm{CaM}$-dependent protein phosphatase (calcineurin or PP-2B), and protein phosphatase 2C (PP-2C) (Shenolikar and Nairn, 1991). Biochemical studies have demonstrated that all of these can be found in the brain (Stemmer and Klee, 1991; Sim, 1992), although PP-1 appears to be specifically enriched in synaptic junctions with respect to cytosolic fractions (Shields et al., 1985).

Examination of the physiological role of protein phosphatases in synaptic transmission has been limited by the lack of specific activators or inhibitors. Recently, however, several relatively specific membrane-permeable inhibitors of PP-1 and PP-2A have become available, okadaic acid and calyculin A (Ishihara et al., 1989; Suganuma et al., 1990). At crayfish and frog neuromuscular junctions, application of okadaic acid has been reported to act presynaptically to increase transmitter release (Swain et al., 1991). It has also recently been shown that inhibition of protein phosphatase activity with okadaic acid, calyculin A, or microcystin LR, a cell-impermeable protein phosphatase inhib- 


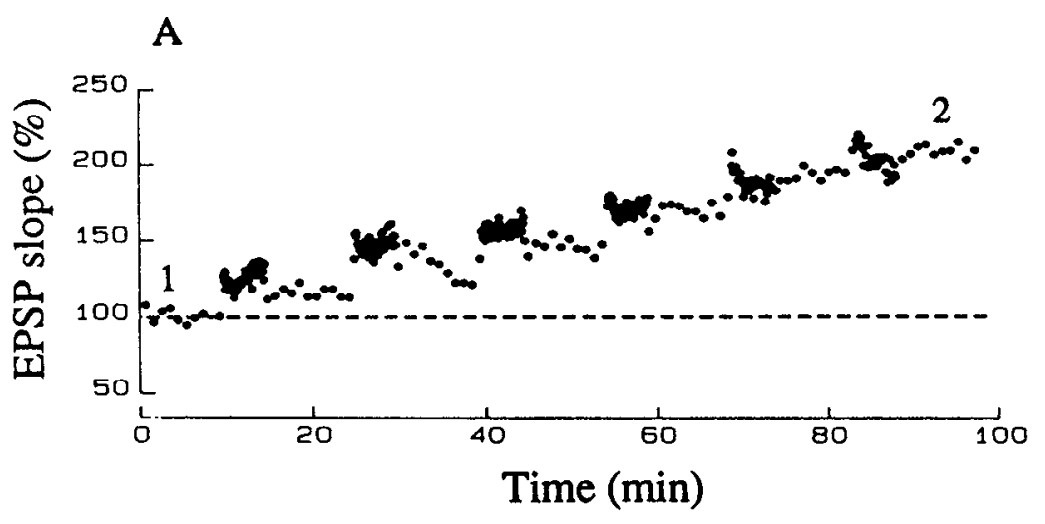

B $\quad 1+2$

$\mathrm{C}$
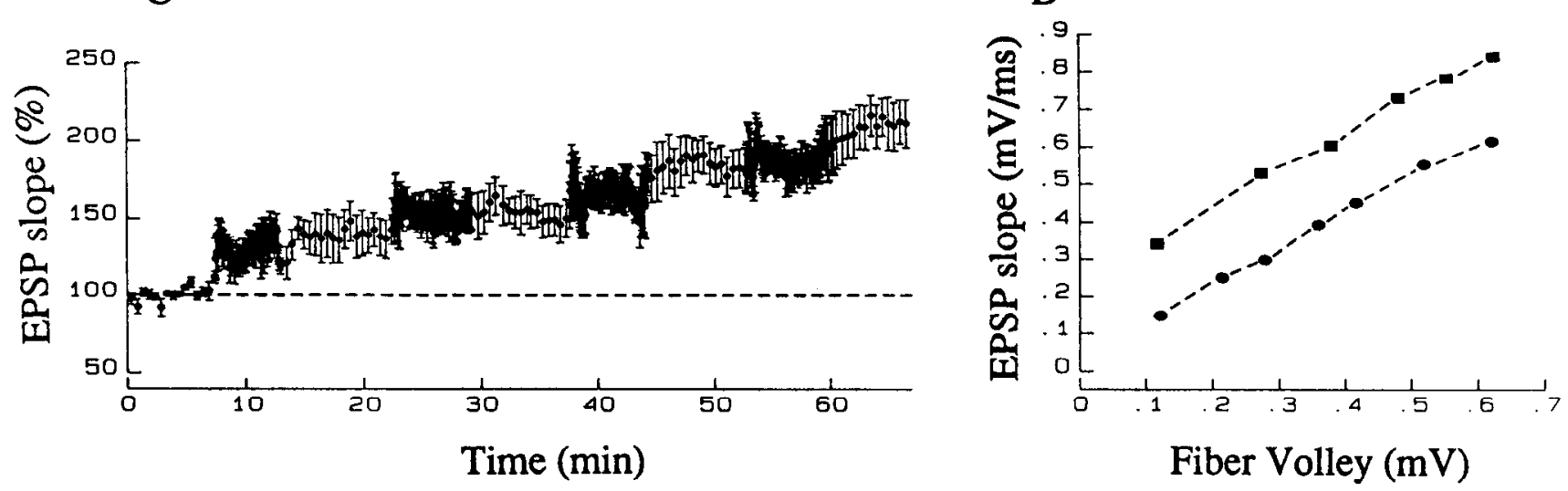

Figure 1. Stimulation $(1 \mathrm{~Hz})$ causes an enhancement of synaptic transmission in hippocampal slices treated with calyculin A. $A$, Plot of a typical experiment in which periods of $1 \mathrm{~Hz}$ stimulation $(5 \mathrm{~min})$ were applied. Each $1 \mathrm{~Hz}$ stimulation period caused an incremental increase in synaptic strength. $B$, Field EPSPs (averages of three successive responses) were taken at the times indicated in $A$. $C$, Plot of averaged data from five experiments in which the interval between each successive period of $1 \mathrm{~Hz}$ stimulation was the same. $D$, Input-output curves generated before (circles) and following (squares) the application of repctitive periods of $1 \mathrm{~Hz}$ stimulation.

itor, blocks homosynaptic long-term depression (LTD) in the hippocampus (Mulkey et al., 1993). Here we report additional effects of calyculin A on synaptic transmission in the CA1 region of rat hippocampal slices. Specifically, pretreatment of slices with calyculin A caused an activity-dependent and input-specific enhancement in synaptic transmission. A number of experimental manipulations indicate that this effect was likely due to activation of presynaptic calcium-dependent protein kinases and the consequent increase in neurotransmitter release.

\section{Materials and Methods}

Standard procedures were used to prepare hippocampal slices from young (12-24 d) Sprague-Dawley rats (Malenka, 1991; Mulkey and Malenka, 1992). The slices were placed on filter paper suspended on a petri dish filled with superfusion medium and maintained in a humidified $95 \% \mathrm{O}_{2}, 5 \% \mathrm{CO}_{2}$ (carbogen) atmosphere at room temperature to recover $(1-6 \mathrm{hr})$. Following recovery, the slices were incubated at room temperature in solution containing $1 \mu \mathrm{M}$ calyculin A saturated with carbogen for a period of 1-3 hr. A slice was then transferred to the recording chamber where it was submerged in a continuously superfusing medium that was saturated with carbogen. The superfusing medium contained $119 \mathrm{~mm} \mathrm{NaCl}, 2.5 \mathrm{mM} \mathrm{KCl}, 1.3 \mathrm{~mm} \mathrm{MgSO}, 1.0 \mathrm{~mm}$ $\mathrm{NaH}_{2} \mathrm{PO}_{4}, 26.2 \mathrm{~mm} \mathrm{NaHCO}, 2.5 \mathrm{mM} \mathrm{CaCl}_{2}$, and $11 \mathrm{~mm}$ glucose. The temperature of the medium was maintained between $28^{\circ} \mathrm{C}$ and $30^{\circ} \mathrm{C}$.

Standard methods were used to make extracellular and whole-cell recordings from CA1 neurons. Extracellular field EPSPs were recorded in stratum radiatum using electrodes (3-6 M $)$ filled with $3 \mathrm{M} \mathrm{NaCl}$. Because calyculin A treatment can affect fiber excitability (Mulkey et al., 1993), in all experiments the presynaptic fiber volley was monitored on line during the course of each experiment and was matched to the control fiber volley recorded prior to any experimental manipulation by making small adjustments in the stimulation voltage. Blind wholecell recordings (Blanton et al., 1989; Coleman and Miller, 1989) were made using electrodes (5-12 M ) filled with $117.5 \mathrm{~mm} \mathrm{~K}$-gluconate, $17.5 \mathrm{~mm} \mathrm{KMeSO}_{4}, 8 \mathrm{~mm} \mathrm{NaCl}, 10 \mathrm{~mm}$ HEPES, $3 \mathrm{~mm} \mathrm{Mg}$-ATP, 0.2 mM GTP, and 0.2 mM EGTA. The solution was adjusted to $\mathrm{pH} 7.2$ and $290 \mathrm{mOsm}$ before the addition of Mg-ATP, which was added just before recording commenced. Afferent fibers in the stratum radiatum were stimulated at $0.1 \mathrm{~Hz}$ using bipolar stainless steel electrodes. Independent fiber bundles in the same slice were activated alternatively by placing stimulating electrodes on opposite sides of the recording electrode. Data were collected and analyzed on line $(5-10 \mathrm{kHz}$ sampling rate) using a 386-based personal computer and personal software written in the Axo-BASIC environment (Axon Instruments). To minimize the contribution of voltage-dependent conductances, initial slopes of the EPSPs were calculated using a least squares regression. Summary graphs were constructed as described (Mulkey and Malenka, 1992). Calyculin A was obtained from LC Services Corporation or from Kamiya Inc; AP5, from Cambridge Research Biochemicals or from Tocris Neuramin.

\section{Results}

All experiments were performed on slices that had been incubated for 1-3 hr in $1 \mu \mathrm{M}$ calyculin $\mathrm{A}$, a membrane-permeable and selective inhibitor of PP-1 and PP-2A (Ishihara et al., 1989; Suganuma et al., 1990). Upon transfer to the recording chamber, afferent stimulation was initiated at $0.1 \mathrm{~Hz}$ to obtain a stable baseline of synaptic responses. This stimulation caused no significant or consistent growth in the synaptic response (Mulkey et al., 1993). When the stimulation frequency was increased to $1 \mathrm{~Hz}$ for 5-10 min, an enhancement in synaptic transmission was observed in 91 of 141 slices $(44 \pm 2.5 \%$, mean percentage 


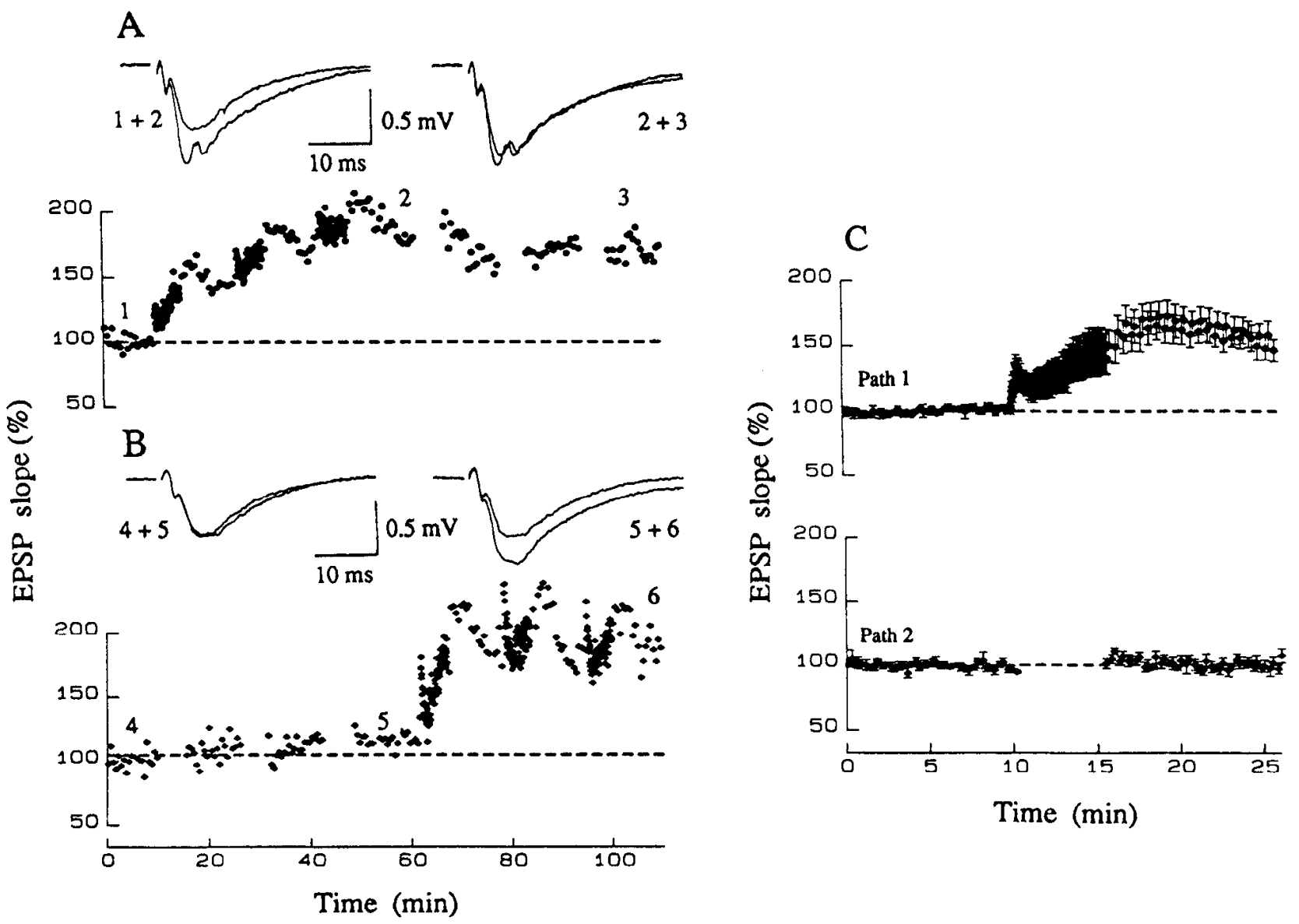

Figure 2. The synaptic enhancement induced by $1 \mathrm{~Hz}$ stimulation is input specific. Field EPSPs were recorded from a single site in response to alternating stimulation of two independent afferent fiber bundles. In path $A$, three successive periods of $1 \mathrm{~Hz}$ stimulation causcd an increasc in synaptic strength with no significant change in the unstimulated path $B$. Subsequent application of similar stimuli to path $B$ caused an increase in synaptic strength with no further potentiation in path $A$. Sample field EPSPs were taken at the times indicated. $C$, Average of eight experiments (mean \pm SEM) demonstrating enhancement in the stimulated path (Path 1 ) and no change in the simultaneously recorded control path (Path 2).

change from baseline \pm SEM, $n=91 ; 28.4 \pm 2.5 \%$, when all 141 slices are included). Figure 1 shows an example of this phenomenon and demonstrates that each successive period of $1 \mathrm{~Hz}$ stimulation caused an additional increase in synaptic efficacy $(110 \pm 10.5 \%$, mean percentage change following four periods of $1 \mathrm{~Hz}$ stimulation, $n=18$ ).

The amplitude of the presynaptic fiber volley frequently increased following $1 \mathrm{~Hz}$ stimulation (Mulkey et al., 1993). To test whether this change in fiber excitability might account for the observed increase in synaptic transmission, input-output curves were obtained before and following the $1 \mathrm{~Hz}$ stimulation $(n=5)$. The observed shift to the left in the input-output curvc (Fig. $1 D$ ) indicates that synaptic transmission was increased independent of any increase in fiber excitability. To control for direct effects on fiber excitability caused by the $1 \mathrm{~Hz}$ stimulation in calyculin A-treated slices, in all experiments the fiber volley amplitude was monitored and adjusted to match the original value that had been recorded during the initial baseline period of the experiment.

Under normal conditions, prolonged $1 \mathrm{~Hz}$ stimulation of the Schaffer collateral-commissural pathway elicits an input- or synapse-specific long-term depression (LTD) in CAl neurons (Dudek and Bear, 1992; Mulkey and Malenka, 1992). An important mechanistic question is whether the synaptic enhancement induced by $1 \mathrm{~Hz}$ stimulation in the presence of calyculin
A is also limited to activated synapses. In Figure $2, A$ and $B$ show an experiment $(n=8)$ in which two independent afferent fiber bundles that synapse on the same population of postsynaptic cells were stimulated alternately. After an initial $10 \mathrm{~min}$ baseline period, the test path received $1 \mathrm{~Hz}$ stimulation resulting in a selective, input-specific increase in synaptic strength. Subsequent $1 \mathrm{~Hz}$ stimulation of the control path also caused an input-specific potentiation similar to that observed in the test path. Averaged data from eight experiments is shown in Figure $2 C$. These results indicate that the synaptic potentiation elicited by $1 \mathrm{~Hz}$ stimulation in the presence of calyculin $\mathrm{A}$ is both input specific and activity dependent.

How does increasing the frequency of stimulation from 0.1 $\mathrm{Hz}$ to $1 \mathrm{~Hz}$ cause an increase in the strength of synaptic transmission? One plausible hypothesis is that the increase in stimulation rate results in a sufficient influx of $\mathrm{Ca}^{2+}$ either pre- or postsynaptically to activate $\mathrm{Ca}^{2+}$-dependent protein kinases. To test this hypothesis, we examined the effects on synaptic transmission of applying $1 \mathrm{~Hz}$ stimulation when $\mathrm{Ca}^{2+}$ influx was prevented by replacing extracellular $\mathrm{Ca}^{2+}$ with magnesium. Figure $3 A$ shows an experiment in which $1 \mathrm{~Hz}$ stimulation was applied under conditions where synaptic transmission was completely blocked by application of medium containing no added $\mathrm{Ca}^{2+}$ and $3.5 \mathrm{~mm} \mathrm{Mg}{ }^{2+}$. Following the $1 \mathrm{~Hz}$ stimulation, perfusion with normal medium ( $2.5 \mathrm{~mm} \mathrm{Ca}{ }^{2+}, 1.3 \mathrm{mM} \mathrm{Mg}^{2+}$ ) re- 


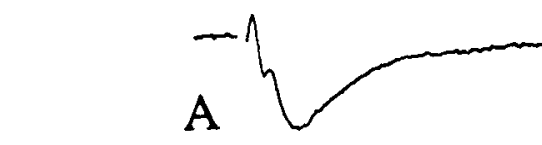

$\frac{0}{0}$
$\frac{0}{0}$
$\frac{0}{2}$
$\frac{2}{x}$
2

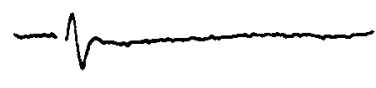

3

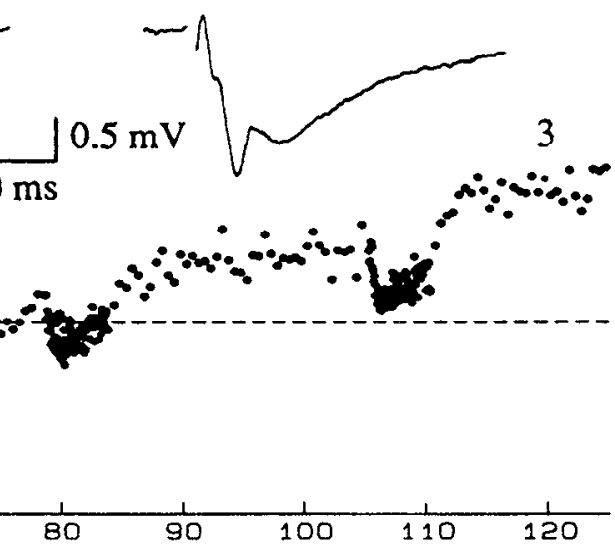

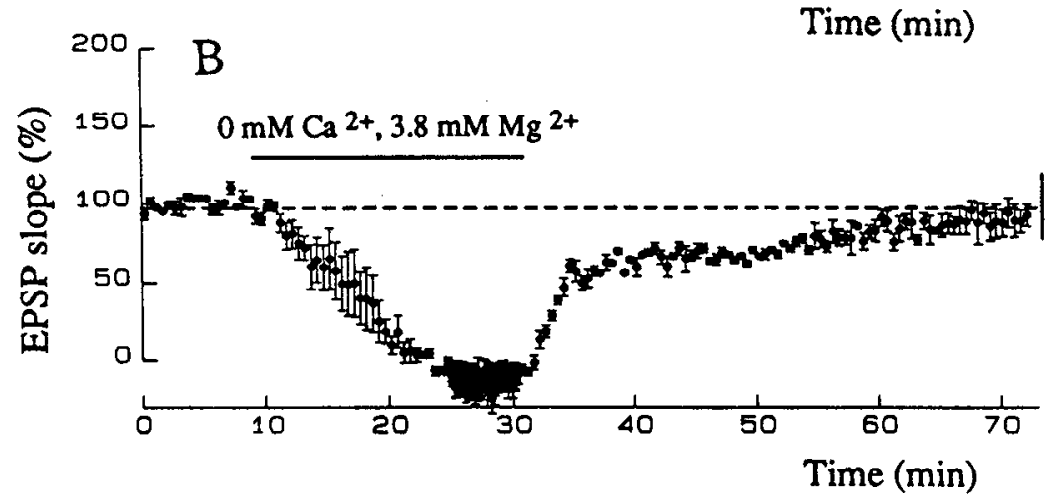
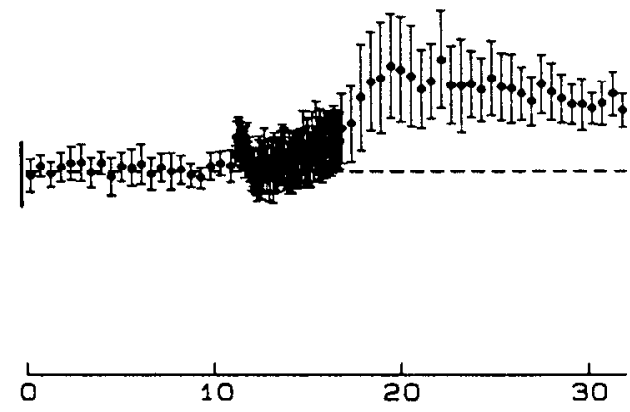

Figure 3. The synaptic enhancement induced by $1 \mathrm{~Hz}$ stimulation is calcium dependent. $A$, Plot of an experiment in which $1 \mathrm{~Hz}(5 \mathrm{~min})$ stimulation was applied after synaptic transmission was blocked by perfusing with medium containing no added $\mathrm{Ca}^{2+}$ and $3.8 \mathrm{mM} \mathrm{Mg}^{2+}$. No synaptic enhancement was observed after reperfusion with control medium $\left(2.5 \mathrm{mM} \mathrm{Ca}^{2+}\right.$ and $\left.1.3 \mathrm{mM} \mathrm{Mg}^{2+}\right)$. Subsequent application of $1 \mathrm{~Hz}(5 \mathrm{~min})$ stimulation now in the presence of normal medium caused synaptic enhancement. Sample field EPSPs were taken at the times indicated. $B$. Average of four experiments similar to that in $A$. The break in the time axis ranged from 0 to $5 \mathrm{~min}$. Data in both portions of the graph were normalized to the original 10 min baseline. Note the different time axis in the right portion of the graph.
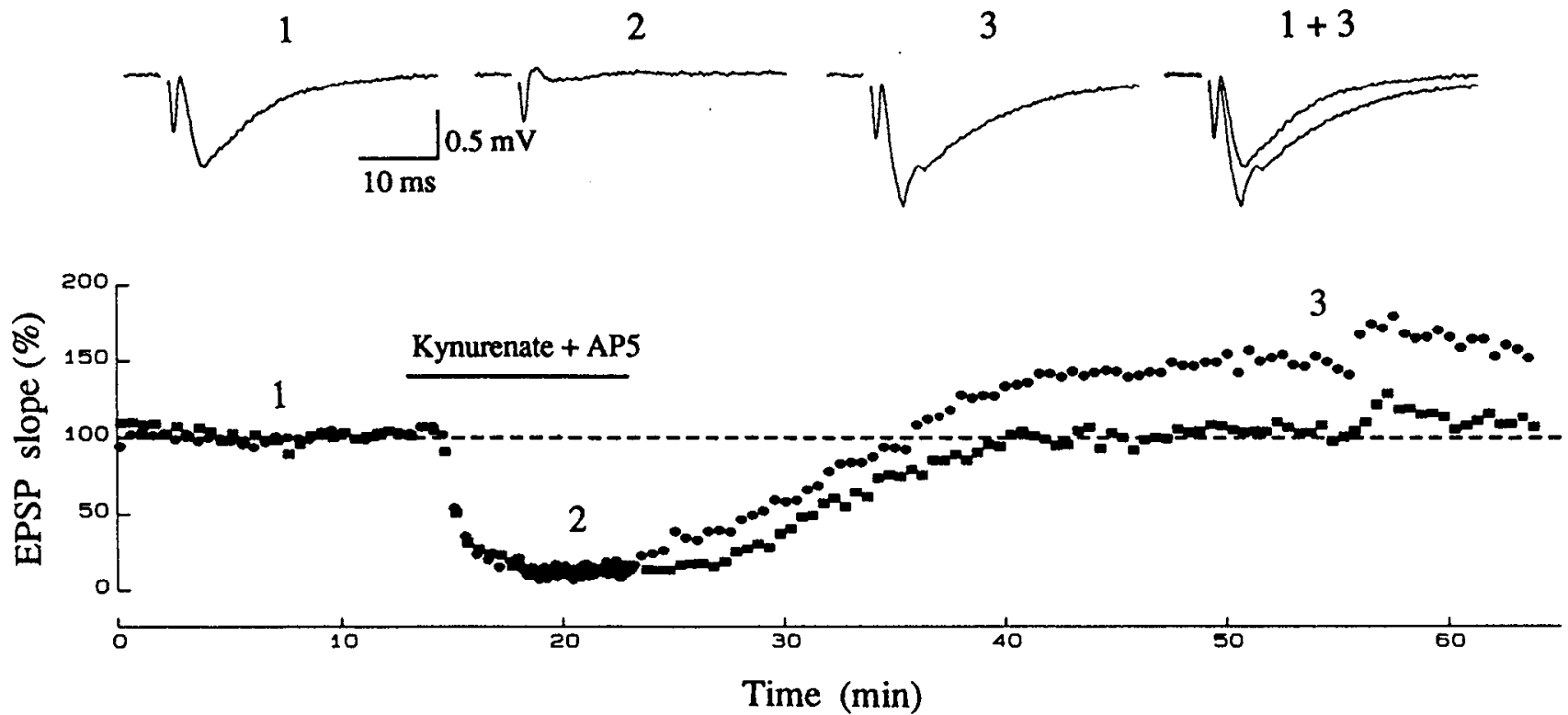

Figure 4. Enhancement of synaplic transmission can still be induced in the presence of glutamate receptor antagonists. Plot of an experiment in which two independent fiber bundles were alternately stimulated and $1 \mathrm{~Hz}(5 \mathrm{~min})$ stimulation was applied to one path (circles) after the postsynaptic responses were blocked by bath application of kynurenate $(2 \mathrm{mM})$ and D-AP5 $(25 \mu \mathrm{M})$. Upon washout of the antagonists there is an enhancement of synaptic transmission in the stimulated path (circles) but not in the unstimulated control path (squares). Sample field EPSPs were taken at the times indicated. 


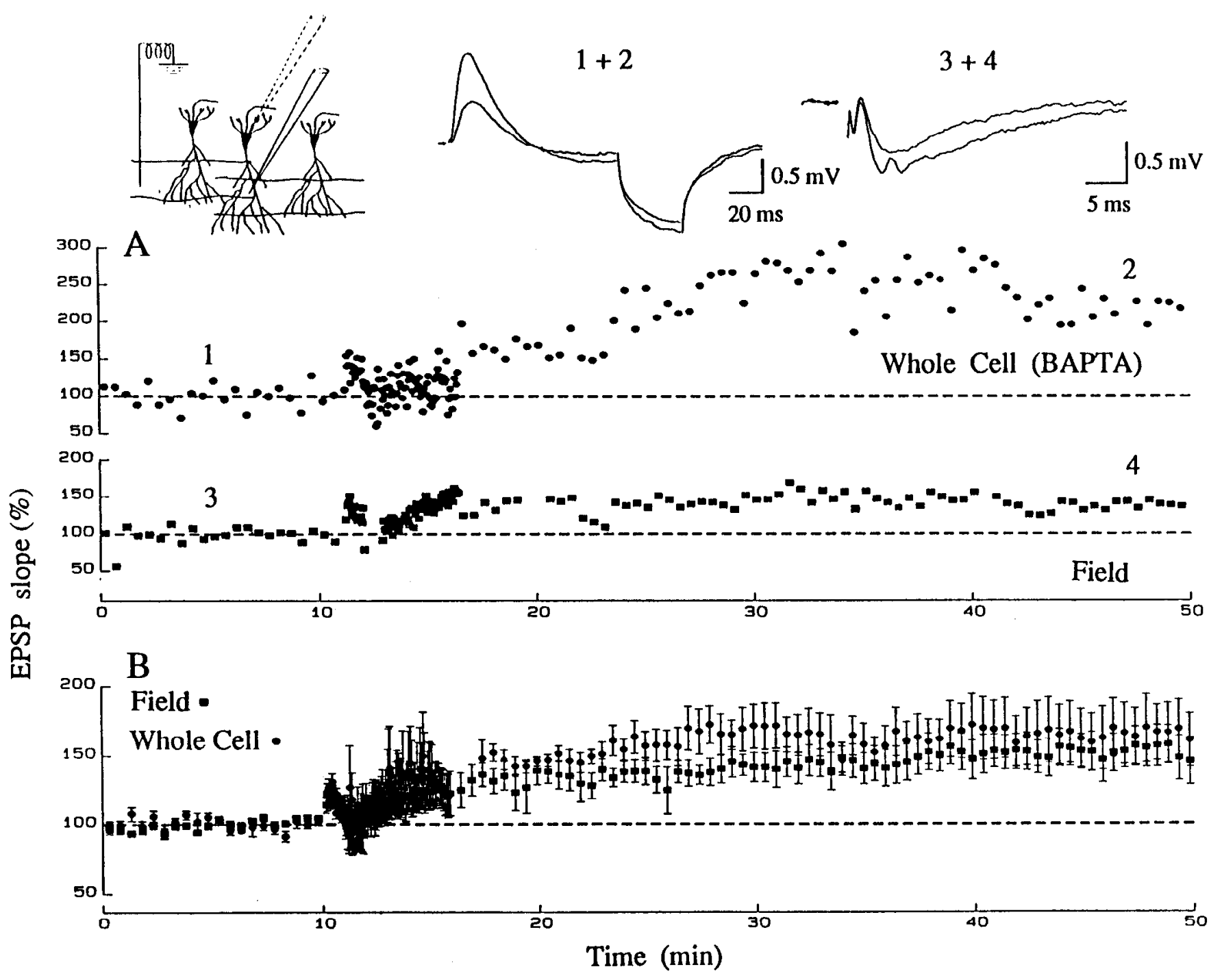

Figure 5. Enhancement of synaptic transmission is not blocked by loading CA1 cells with BAPTA. A:Top left, Diagram showing recording arrangement. Individual cells were loaded with BAPTA and EPSPs were recorded using whole-cell recording while field EPSPs were recorded simultaneously with an extracellular electrode placed in the dendritic field. Below is a plot of a typical experiment showing an increase in synaptic strength following $1 \mathrm{~Hz}(5 \mathrm{~min})$ stimulation both in the cell (circles) and the field (squares). The whole-cell recording electrode contained $10 \mathrm{~mm}$ BAPTA. Sample EPSPs were taken at the times indicated. $B$. Average of seven experiments (mean \pm SEM) like that in $A$ showing the effects of 1 $\mathrm{Hz}$ stimulation in BAPTA-filled cells (circles) and the field EPSPs (squares).

sulted in the recovery of the synaptic responses to the original baseline value. After responses had stabilized, $1 \mathrm{~Hz}$ stimulation was again applied and this resulted in an increase in the synaptic response, which was augmented by subsequent periods of $1 \mathrm{~Hz}$ stimulation. Figure $3 B$ shows averaged data from four such experiments with an increase in the EPSP slope following $1 \mathrm{~Hz}$ stimulation in the absence of $\mathrm{Ca}^{2+}$ of $4 \pm 2 \%$ and $44 \pm 7 \%$ when normal $\mathrm{Ca}^{2+}$-containing medium had been reperfused.

The previous experiment demonstrates that the synaptic potentiation elicited by $1 \mathrm{~Hz}$ stimulation is $\mathrm{Ca}^{2+}$ dependent. To determine if the requisite $\mathrm{Ca}^{2+}$ influx occurs pre- or postsynaptically, two pathway experiments were performed in which $1 \mathrm{~Hz}$ stimulation was applied to the test path after synaptic transmission was completcly blocked by application of the glutamate receptor antagonists kynurenate $(2 \mathrm{mM})$ and D-2-amino5-phosphonovalerate (D-AP5; $25 \mu \mathrm{M}$ ) (Fig. 4). Upon washout of the antagonists there was a clear enhancement in the test path $(28 \pm 13 \%, n=4)$. This result indicates that the synaptic en- hancement elicited by $1 \mathrm{~Hz}$ stimulation does not require activation of postsynaptic ionotropic glutamate receptors or postsynaptic voltage-dependent $\mathrm{Ca}^{2+}$ channels, the activation of which would depend on the depolarization provided by the EPSP generated by postsynaptic glutamate reccptors.

To test further if an increase in the postsynaptic $\mathrm{Ca}^{2+}$ concentration is necessary for the synaptic enhancement elicited by $1 \mathrm{~Hz}$ stimulation, cells were loaded with the $\mathrm{Ca}^{2+}$ chelator BAPTA by recording with patch pipettes containing a high concentration (10 mM) of this compound. Extracellular field EPSPs were recorded simultaneously to monitor fiber volley amplitude and also to record the consequences of $1 \mathrm{~Hz}$ stimulation in neighboring cells. Figure $5 A$ shows an example of a typical experiment and demonstrates that $1 \mathrm{~Hz}$ stimulation caused a significant increase in synaptic transmission both in the field EPSP and in a cell loaded with BAPTA. Figure $5 B$ shows averaged data with a mean increase in the EPSP slope of $50 \pm 5 \%$ in the field and $67 \pm 9 \%(n=7)$ in cells loaded with BAPTA. 


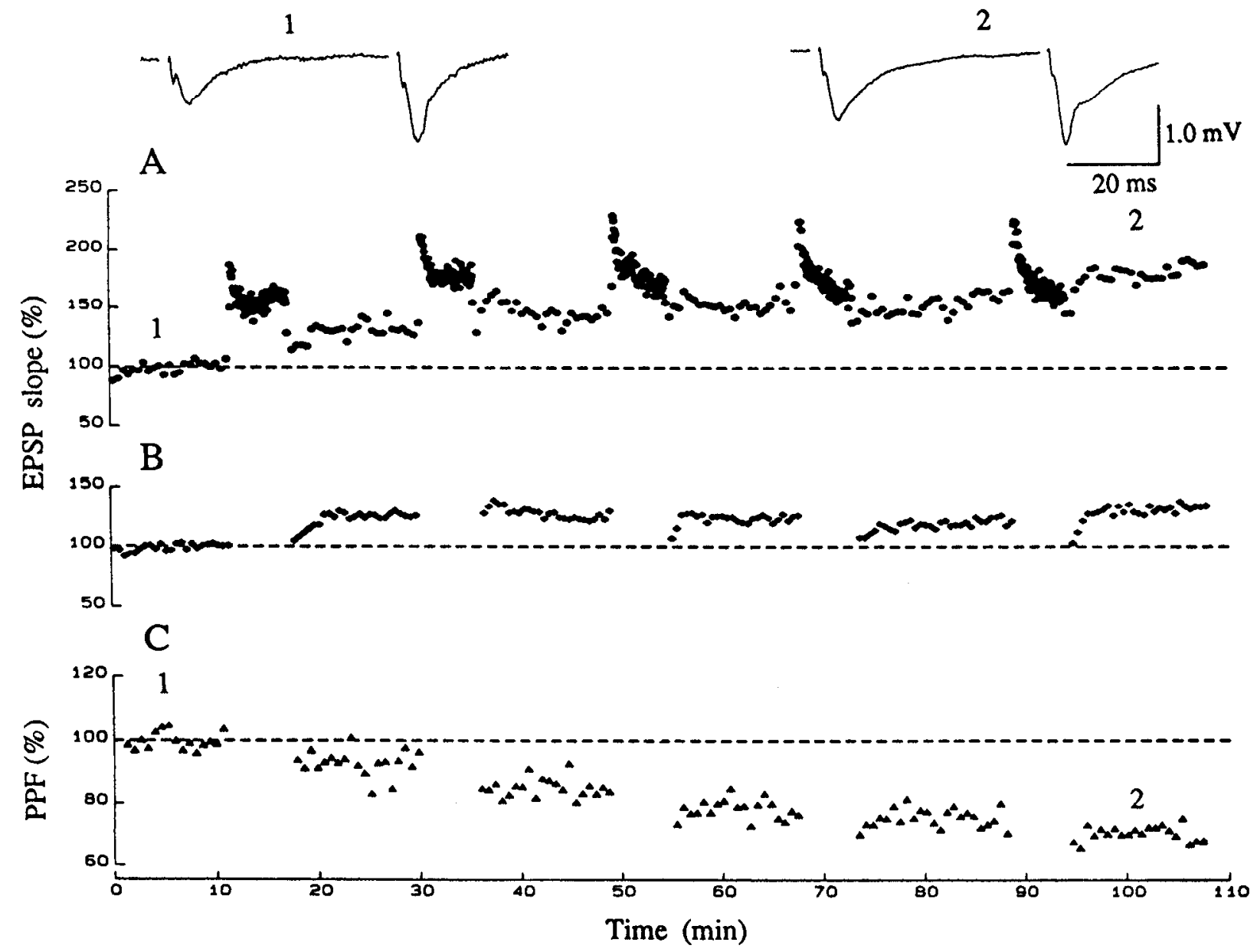

Figure 6. Enhancement of synaptic transmission by $1 \mathrm{~Hz}$ stimulation decreases paired-pulse facilitation $(P P F)$. Paired stimuli (50 msec interstimulus interval) were applied throughout the course of the experiment except during the periods of $1 \mathrm{~Hz}$ stimulation. $A$, Plot of field EPSP slope evoked by the first stimulus. $B$, Plot of field EPSP slope evoked by the second stimulus. $C$. Plot of normalized paired-pulse ratio. The PPF ratio during the course of the experiment was normalized with respect to that recorded during the initial 10 min baseline period. A decrease in PPF was observed following each successive $1 \mathrm{~Hz}$ stimulation period. Field EPSPs were taken at the times indicated.

The inability of glutamate receptor antagonists or postsynaptic BAPTA to block the synaptic enhancement elicited by 1 $\mathrm{Hz}$ stimulation suggests that the predominant mechanism activated by this stimulation is localized presynaptically. It is generally accepted that paired-pulse facilitation (PPF) is a presynaptic phenomenon that is influenced by manipulations that alter transmitter release (Mallart and Martin, 1968; Zucker, 1989; Manabe et al., 1993). We therefore examined the interaction of the stimulus-induced synaptic enhancement with PPF. Figure 6 shows an experiment $(n=8)$ in which PPF ( $50 \mathrm{msec}$ interpulse interval) was monitored continuously before and following periods of $1 \mathrm{~Hz}$ stimulation. Following each successive period of $1 \mathrm{~Hz}$ stimulation there was a clear decrease in PPF (six of eight experiments) such that following the fourth $1 \mathrm{~Hz}$ stimulation period, the PPF ratio had decreased by $29.5 \pm 6 \%$ and the field EPSP slope had increased by $95 \pm 18 \%(n=6)$. The decrease in PPF was not due to the increase in the size of the field EPSP, and the consequent problems associated with nonlinear summation (Martin, 1955), since the change in PPF was still present when, at the end of the experiment, stimulation strength was reduced so that the field EPSP slope matched that recorded during the initial baseline period.

The decrease in PPF following the synaptic enhancement is consistent with the hypothesis that $1 \mathrm{~Hz}$ stimulation in calyculin A-treated slices causes an increase in evoked transmitter release. This hypothesis predicts that the NMDA receptor-mediated component of the EPSP should also be enhanced following 1 $\mathrm{Hz}$ stimulation since synaptically released glutamate activates both non-NMDA and NMDA receptors (Collingridge and Lester, 1989). To examine the NMDA receptor-mediated component of the response, experiments were performed in the presence of the non-NMDA receptor antagonist 6-cyano-7nitroquinoxalinedione (CNQX; $10 \mu \mathrm{M})$ and low extracellular $\mathrm{Mg}^{2+}(0.1 \mathrm{~mm})$. In all experiments, there was a clear increase ( $66 \pm 5 \%$ following two periods of stimulation; $n=4$ ) in the EPSP. The potentiated response was completely blocked by the subsequent application of D-AP5 $(50 \mu \mathrm{M}$; Fig. $7 A)$. Averaged data from four experiments is shown in Figure $7 B$.

\section{Discussion}

This study demonstrates that following the inhibition of protein phosphatase activity with calyculin A, stimulation of Schaffer collateral/commissural afferents at $1 \mathrm{~Hz}$ elicits a synaptic enhancement rather than the normally observed synaptic depression (Dudek and Bear, 1992; Mulkey and Malenka, 1992). Several lines of evidence suggest that this is predominantly due to 

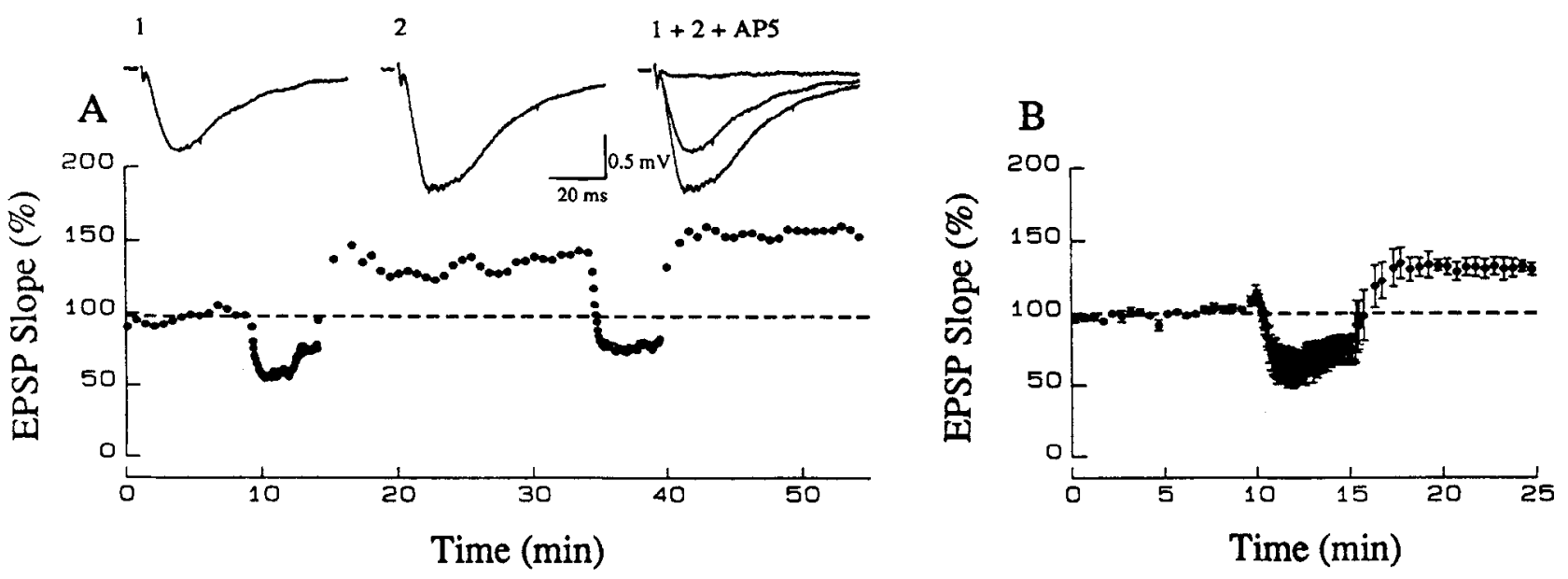

Figure 7. Stimulation $(1 \mathrm{~Hz}$ ) elicits an enhancement of the NMDA receptor-mediated EPSP. A, Plot of an experiment in which NMDA receptormediated field EPSPs were isolated by applying $10 \mu \mathrm{M} C N Q X$ and $0.1 \mathrm{mM} \mathrm{Mg}{ }^{2+}$. Each period of $1 \mathrm{~Hz}(5 \mathrm{~min})$ stimulation caused a clear increase in the EPSP. Application of $50 \mu \mathrm{M}$ D-AP5 at the end of the experiment $(1+2+A P 5)$ completely blocked the EPSP. Sample field EPSPs were taken at the times indicated. $B$, Average of four experiments (mean $\pm \mathrm{SEM}$ ) like that in $A$.

activation of presynaptic $\mathrm{Ca}^{2+}$-dependent processes. First, the enhancement is reduced when $\mathrm{Ca}^{2+}$ influx into neuronal elements is prevented by the removal of extracellular $\mathrm{Ca}^{2+}$. Second, the enhancement can still be induced, in the presence of $\mathrm{Ca}^{2+}$, when synaptic responses are completely blocked by NMDA and non-NMDA glutamate receptor antagonists. Third, it can also be observed when changes in the postsynaptic $\mathrm{Ca}^{2+}$ concentration are prevented by loading cells with BAPTA. Fourth, the potentiation of synaptic transmission is accompanied by a decrease in paired-pulse facilitation, and this routinely occurs following other experimental manipulations known to enhance transmitter release (Mallart and Martin, 1968; Creager et al., 1980; Zucker et al., 1989; Manabe et al., 1993). Fifth, the NMDA receptor-mediated component of the EPSP also is enhanced by $1 \mathrm{~Hz}$ stimulation in calyculin A-treated slices. Like the decrease in PPF, this simultaneous increase in the two EPSP components is observed following manipulations that enhance transmitter release (Perkel and Nicoll, 1993).

The induction mechanisms for the observed enhancement are clearly different from those required for NMDA receptor-dependent long-term potentiation as they do not depend on the activation of postsynaptic glutamate receptors and are not prevented by the inclusion of BAPTA in the patch pipette. The most likely mechanism that would account for the observed increase in synaptic efficacy is that following the inhibition of PP- 1 and PP-2A by calyculin A, $1 \mathrm{~Hz}$ afferent stimulation is sufficient to cause activation of presynaptic $\mathrm{Ca}^{2+}$-dependent protein kinases. This may occur because the interval between successive stimuli is sufficiently short so as to permit temporal summation of the individual presynaptic $\mathrm{Ca}^{2+}$ transients elicited by each stimulus. It must be assumed that this did not occur to an appreciable extent during the $0.1 \mathrm{~Hz}$ afferent stimulation used when collecting baseline responses since no significant growth of synaptic responses was observed. Taken together, these results demonstrate that presynaptic protein kinases are strongly influenced by the frequency of afferent activity. Under normal conditions, any increase in protein kinase activity is balanced by the action of protein phosphatases. However, in the presence of calyculin A, phosphoproteins, which are substrates for the activated kinase(s), would presumably remain in the phosphorylated state. This conclusion rests on the assump- tion that the effects of calyculin A are limited to the inhibition of PP-1 and PP-2A. Treatment of slices with okadaic acid, another commonly used inhibitor of protein phosphatases, did not reliably elicit the same results as those obtained from slices treated with calyculin A. This is likely due to the lower potency and perhaps the lower permeability of okadaic acid (Ishihara et al., 1989; Cohen et al., 1990).

Several protein kinases have been implicated in the modulation of transmitter release and in synaptic plasticity (Walaas and Greengard, 1991). The three most likcly candidates for mediating the phenomenon presented here are CaMKII, PKC, and PKA. A large body of evidence suggests a role for presynaptic CaMKII in regulating neurotransmitter release (Walaas and Greengard, 1991; Greengard et al., 1993). For example, in the squid giant axon and the goldfish mauthner cell preparations, presynaptic injection of CaMKII causes an enhancement of evoked transmitter release (Llinas et al., 1985; Hackett et al., 1990), as does the introduction of CaMKII into rat brain synaptosomes (Nichols et al., 1990). In the hippocampus, inhibition of presynaptic CaMKII depresses synaptic transmission (Waxham et al., 1993), while high-frequency stimulation can result in an increase in CaMKII activity, although this may be localized to the postsynaptic cell (Fukunaga et al., 1993).

A role for presynaptic PKC activity in modifying synaptic transmission is also supported by a large body of evidence (Walaas and Greengard, 1991). In the hippocampus, activation of PKC with phorbol esters potentiates evoked and spontaneous synaptic transmission (Malenka et al., 1986, 1987; Gustafsson et al., 1988; Malinow et al., 1988; Muller et al., 1988) at least in part by enhancing transmitter release (Malenka et al., 1987). Like the potentiation described here, the phorbol ester-induced potentiation also is associated with a decrease in PPF (Gustafsson et al., 1988; Muller et al., 1988). Presynaptic PKC could be activated either directly by a rise in $\mathrm{Ca}^{2+}$ concentration (Nishizuka, 1986) or perhaps by an increase in phosphoinositide turnover due to repetitive activation of presynaptic mGluRs that normally function to depress synaptic transmission (Baskys and Malenka, 1991).

Another kinase that may be involved is PKA, although the evidence in support of its role in modulating transmitter release derives largely from work on invertebrate preparations (Walaas 
and Greengard, 1991). Recently, it has been reported that raising cAMP levels in the hippocampus with forskolin does enhance synaptic transmission (Chavez-Noricga and Stevens, 1992, 1994), as does extracellular application of membrane-permeable cAMP analogs (Frey et al., 1993). This synaptic enhancement is accompanied by an increase in both evoked and spontaneous neurotransmitter release (Chavez-Noriega and Stevens, 1994), indicating a presynaptic site of action for PKA.

The specific set of presynaptic substrate phosphoproteins that are responsible for the synaptic enhancement elicited following activation of any specific protein kinases in the hippocampus is not known. Prominent possibilities include several species of voltage-dependent ion channels, all of which can be affected by protein kinases in a manner that might enhance synaptic transmission (Levitan, 1994), or presynaptic phosphoproteins, such as synapsin I, which interact with synaptic vesicles (Greengard et al., 1993). Whichever phosphoproteins are involved in mediating the synaptic enhancement demonstrated here, these results suggest that like postsynaptic protein phosphatases (Wang et al., 1991; Mulkey et al., 1993), presynaptic protein phosphatases also play a fundamental role in controlling synaptic efficacy following repetitive synaptic activity.

\section{References}

Baskys A, Malenka RC (1991) Antagonists at metabotropic glutamate receptors presynaptically inhibit EPSCs in neonatal rat hippocampus. J.Physiol (Lond) 444:687-701.

Blanton M, LoTurco J, Krigstein A (1989) Whole cell recording from neurons in slices in reptilian and mammalian cerebral cortex. $\mathrm{J}$ Neurosci Methods 30:203-210.

Bliss TV, Collingridge GL (1993) A synaptic model of memory: longterm potentiation in the hippocampus. Nature 361:31-39.

Chavez-Noriega LE, Stevens CF (1992) Modulation of synaptic efficacy in field CA1 of the rat hippocampus by forskolin. Brain Res 574: $85-92$.

Chavez-Noriega LE, Stevens CF (1994) Increased transmitter release at excitatory synapses produced by direct activation of adenylate cyclase in rat hippocampal slices. J Neurosci 14:310-317.

Cohen P, Holmes CF, Tsukitani Y (1990) Okadaic acid: a new probe for the study of cellular regulation. Trends Biol Sci 15:98-102.

Coleman PA, Miller RF (1989) Measurement of passive membrane properties with whole-cell recordings from neurons in the intact amphibian retina. J Neurophysiol 61:218-230.

Collingridge GL, Lester RAJ (1989) Excitatory amino acid receptors in the vertebrate central nervous system. Pharmacol Rev 40:143-210.

Creager R, Dunwiddie T, Lynch G (1980) Paired-pulse and frequency facilitation in the CAl region of the in vitro rat hippocampus. J Physiol (Lond) 299:409-424.

Dudek SM, Bear MF (1992) Homosynaptic long-term depression in area CAl of the hippocampus and effects of $N$-methyl-D-aspartate blockade. Proc Natl Acad Sci USA 89:4363-4367.

Frey U, Wang Y-Y, Kandel ER (1993) Effects of cAMP simulate a late stage of LTP in hippocampal CAl neurons. Science 260:16611664.

Fukunaga K, Stoppini L, Miyamoto E, Muller D (1993) Long-term potentiation is associated with an increased activity of calcium/calmodulin-dependent protein kinase II. J Biol Chem 268:7863-7867.

Greengard P, Valtorta F, Czernik AJ, Benfenati F (1993) Synaptic vesicle phosphoproteins and regulation of synaptic function. Science 259:780-784

Gustafsson B, Huang Y-Y, Wigstrom H (1988) Phorbol ester-induced synaptic potentiation differs from long-term potentiation in the guinea pig hippocampus in vitro. Neurosci Lett 85:77-81.

Hackett JT, Cochran SL, Greenfield LJ Jr, Brocius DC, Ueda T (1990) Synapsin I injected presynaptically into goldfish Mauthner axons reduces quantal synaptic release. J Neurophysiol 63:701-706.

Ishihara H, Martin BL, Braytigan DL, Karaki H, Ozaki H, Kato Y, Fusetani N, Watabe S, Hashimoto K, Uemura D, Hartshorne DJ (1989) Calyculin A and okadaic acid: inhibitors of protein phosphatase activity. Biochem Biophys Res Commun 159:871-877.
Levitan IB (1994) Modulation of ion channels by protein phosphorylation and dephosphorylation. Annu Rev Physiol 56: in press.

Llinas RR, McGuinness TL, Leonard CS, Sugimori M, Greengard P (1985) Intraterminal injection of synapsin 1 or calcium/calmodulindependent protein kinase II alters neurotransmitter release. Proc Natl Acad Sci USA 82:3035-3039.

Madison DV, Malenka RC, Nicoll RA (1991) Mechanisms underlying long-term potentiation of synaptic transmission. Annu Rev Neurosci 14:379-397.

Malenka RC (1991) Postsynaptic factors control the duration of synaptic enhancement in area CAl of the hippocampus. Neuron 6:5360 .

Malenka RC, Madison DV, Nicoll RA (1986) Potentiation of synaptic transmission in the hippocampus by phorbol esters. Nature 321:175177.

Malenka RC, Ayoub GS, Nicoll RA (1987) Phorbol esters enhance neurotransmitter release in rat hippocampal slices. Brain Res 403: 198-203.

Malinow R, Madison D, Tsien RW (1988) Persistent protein kinase activity underlying long-term potentiation. Nature 335:820-824.

Mallart A, Martin AR (1968) The relation between quantum content and facilitation at the neuromuscular junction of the frog. J Physiol (Lond) 196:593-604.

Manabe T, Wyllie DJ, Perkel DJ, Nicoll RA (1993) Modulation of synaptic transmission and long term potentiation: effects on paired pulse facilitation and EPSC variance in the CA1 region of the hippocampus. J Neurophysiol 70:1451-1459.

Martin AR (1955) Further study of the statistical composition of the end-plate potential. J Physiol (Lond) 130:114-122.

Mulkey RM, Malenka RC (1992) Mechanisms underlying induction of homosynaptic long-term depression in area CA1 of the hippocampus. Neuron 9:967-975.

Mulkey RM, Herron CE, Malenka RC (1993) An essential role for protein phosphatases in hippocampal long-term depression. Science 261:1051-1055.

Muller D, Turnbull J, Baudry M, Lynch G (1988) Phorbol esterinduced synaptic facilitation is diffcrent than long-term potentiation. Proc Natl Acad Sci USA 85:6997-7000.

Nichols RA, Sihra TS, Czernik AJ, Nairn AC, Greengard P (1990) Calcium/calmodulin-dependent protein kinase II increases glutamate and noradrenaline release from synaptosomes. Nature 343:647-651.

Nishizuka Y (1986) Studies and perspectives of protein kinase C. Science 233:305-312.

Perkel DJ, Nicoll RA (1993) Evidence for all-or-none regulation of neurotransmitter release: implications for long-term potentiation. $J$ Physiol (Lond) 471:481-500.

Schulman H (1991) Serine/threonine kinases in the nervous system. Curr Opin Neurobiol 1:43-52.

Shenolikar S, Nairn AC (1991) Protein phosphatases: recent progress. Adv Second Messenger Phosphoprotein Res 23:1-121.

Shiclds SM, Ingebritsen TS, Kelly P (1985) Identification of protein phosphatase $I$ in synaptic junctions: dephosphorylation of endogenous $\mathrm{Ca} / \mathrm{calmodulin}$-dependent kinase II and synapse-enriched phosphoproteins. J Neurosci 5:3414-3422.

Sim AT (1992) The regulation and function of protein phosphatases in the brain. Mol Neurobiol 5:229-246.

Stemmer P, Klee CB (1991) Serine/threonine phosphatases in the nervous system. Curr Opin Neurobiol 1:53-64.

Suganuma M, Fujiki H, Furuya-Suguri H, Yoshizawa S, Yasumoto S, Kato Y, Fusetani N, Sugimura T (1990) Calyculin A, an inhibitor of protein phosphatases, a potent tumor promoter on CD-1 mouse skin. Cancer Res 50:3521-3525.

Swain JE, Robitaille R, Dass GR, Charlton MP (1991) Phosphatases modulate transmission and serotonin facilitation at synapses: studies with the inhibitor okadaic acid. J Neurobiol 22:855-864.

Walaas SI, Greengard P (1991) Protein phosphorylation and neuronal function. Pharmacol Rev 43:299-349.

Wang L, Salter M, MacDonald JF (1991) Regulation of kainate receptors by cAMP-dependent protein kinase and phosphatases. Science 253:1132-1135.

Waxham MN, Malenka RC, Kelly PT, Mauk M (1993) Calcium/ calmodulin dependent protein kinase II regulates hippocampal synaptic transmission. Brain Res 609:1-8.

Zucker RS (1989) Short-term synaptic plasticity. Annu Rev Neurosci 12:13-31. 